\title{
Parylene-based electret power generators
}

\author{
Hsi-wen Lo and Yu-Chong Tai \\ Department of Electrical Engineering, California Institute of Technology, 1200 East California \\ Boulevard Pasadena, CA 91125, USA \\ E-mail: lo@caltech.edu
}

Received 4 April 2008, in final form 20 June 2008

Published 29 September 2008

Online at stacks.iop.org/JMM/18/104006

\begin{abstract}
An electret power generator is developed using a new electret made of a charged parylene $\mathrm{HT}^{\circledR}$ thin-film polymer. Here, parylene $\mathrm{HT}^{\circledR}$ is a room-temperature chemical-vapor-deposited thin-film polymer that is MEMS and CMOS compatible. With corona charge implantation, the surface charge density of parylene $\mathrm{HT}^{\circledR}$ is measured as high as $3.69 \mathrm{mC} \mathrm{m}^{-2}$. Moreover, it is found that, with annealing at $400{ }^{\circ} \mathrm{C}$ for $1 \mathrm{~h}$ before charge implantation, both the long-term stability and the high-temperature reliability of the electret are improved. For the generator, a new design of the stator/rotor is also developed. The new micro electret generator does not require any sophisticated gap-controlling structure such as tethers. With the conformal coating capability of parylene $\mathrm{HT}^{\mathbb{R}}$, it is also feasible to have the electret on the rotors, which is made of either a piece of metal or an insulator. The maximum power output, $17.98 \mu \mathrm{W}$, is obtained at $50 \mathrm{~Hz}$ with an external load of $80 \mathrm{M} \Omega$. For low frequencies, the generator can harvest $7.7 \mu \mathrm{W}$ at $10 \mathrm{~Hz}$ and $8.23 \mu \mathrm{W}$ at $20 \mathrm{~Hz}$.
\end{abstract}

(Some figures in this article are in colour only in the electronic version)

\section{Introduction}

Energy harvesting systems, aiming to scavenge power from environmental sources and produce electricity, have gained much research interest during the past decade. One promising application of the harvesters is to provide power for distributed wireless sensor motes. So far, most wireless sensor motes are powered by batteries and long-term continuous power supply is one of the major challenges. If continuous power can be harvested from the environment, these sensor motes can then be 'set and forget'. There are many possible energy sources in our daily life such as human/animal motions [11, 13, 19], human/animal body heat [23], natural vibrations and vibrations of moving vehicles [4, 18, 25], etc. Among them, linear vibrational motions are of special interest. Three paradigms have been developed to harvest energy from linear vibration motion by electromagnetic, piezoelectric and electrostatic methods. Electromagnetic power generators generate power when conductors, usually in the form of coils, cut across a magnetic field from a magnet $[10,27,28]$. Devices utilizing the piezoelectric paradigm $[7,15,17]$ often involve flexible suspension beams that are made of or coated with piezoelectric materials such as lead zirconium titanate (PZT). The piezoelectric elements can deform with environmental movements and therefore produce electric power. Electrostatic micro power generators then use variable capacitors that are biased with external voltage sources (e.g., voltage-constrained) [14, 22] or self-biased with electret material (e.g., charge-constrained) [4, 12, 20, 25]. Capacitance of the variable capacitor changes with linear motions and produces power under a voltage or charge constraint. However, almost all these micro power generators use some form of suspension (i.e. tethered) structures and, therefore, are limited to operations at their resonant frequencies. Interestingly, however, most environmental vibrations typically have most energy distributed below $100 \mathrm{~Hz}$ so the ideal resonant frequency should be low [29]. Macro power generators can have low resonant frequencies around $20 \mathrm{~Hz}$ [6], but they are bulky. On the other hand, micro power generators are small but are usually with resonant frequencies above $100 \mathrm{~Hz}$. Therefore, it is our goal to develop micro power generators that do not have tethers to the rotors (i.e. with a resonant frequency near zero) and, therefore, have a wide bandwidth covering the energy-rich low-frequency band. In fact, our previous works demonstrated the first micro power generators free of tethers to harvest power from mechanical motions. Boland et al [3] demonstrated a rotational power generator, while Boland et al [4, 5] illustrated electrostatic generators using mercury rotors confined within chambers with some charged Teflon AF electrets. This work is then 


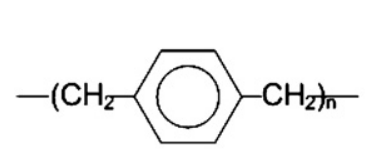

Parylene $\mathrm{N}$<smiles>CCc1ccc(CC)c(Cl)c1</smiles>

Parylene C

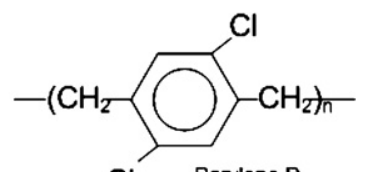

Cl Parylene D

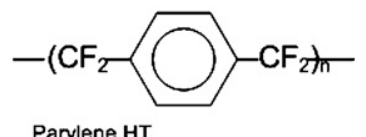

Parylene HT
Figure 1. Typical commercially available parylene variants.

Table 1. Charge densities of common electret materials.

\begin{tabular}{ll}
\hline Electret material & Charge density $\left(\mathrm{mC} \mathrm{m}^{-2}\right)$ \\
\hline Oxide/nitride & $11.51[1]$ \\
Teflon AF & $0.5[8]$ \\
CYTOP & $1.37[25]$ \\
Parylene HT ${ }^{\circledR}$ & 3.69 \\
\hline
\end{tabular}

to develop a solid-state micro generator with improvements in both electrets and structural designs.

\section{Thin-film parylene $\mathbf{H T}^{\circledR}$ electret}

\subsection{Other electret materials}

An electret is an insulating material that exhibits a net electrical charge or dipole moment. The net charge or dipole moment in the electret can be used to provide a biasing electric field such as for an MEMS electret microphone [8,9]. Electrets are also useful for electrostatic generators. In fact, different electret materials have been studied for micro power generators. Boland et al made power generators with Teflon $\mathrm{AF}^{\circledR}$ as the electret [3-5]. Tsutsumino et al developed CYTOP ${ }^{\circledR}$-based power generators [24, 25]. Sterken et al demonstrated silicon oxide/silicon nitride electret micro power generators [20, 21]. Among various electret materials, polymers such as Teflon and CYTOP ${ }^{\circledR}$ are of research interests because of their ease of processing. Although an oxide/nitride electret could have higher charge densities [1], high-temperature processes often render them inferior to polymer counterparts in certain applications. In any case, the charge density is an important parameter for electrets. Table 1 lists some typical charge densities of common electret materials.

\subsection{Parylene $H T^{\circledR}$ as a new electret material}

Parylene, or poly(p-xylylene), is a useful transparent polymer. It has been used in a wide range of applications, particularly as a protective coating for biomedical devices and microelectronics. Its desirable properties include chemical inertness, conformal coating and excellent barrier properties. Commonly available parylene variants are parylene $\mathrm{C}, \mathrm{N}$ and D. Recently, parylene $\mathrm{HT}^{\circledR}$ (figure 1) was announced by Specialty Coating Systems (Indianapolis, IN, USA). Parylene $\mathrm{HT}^{\circledR}$, like other parylenes, is also obtained by chemical vapor deposition at room temperature and can be patterned with an oxygen plasma using photoresist masks. In 1980, Raschke

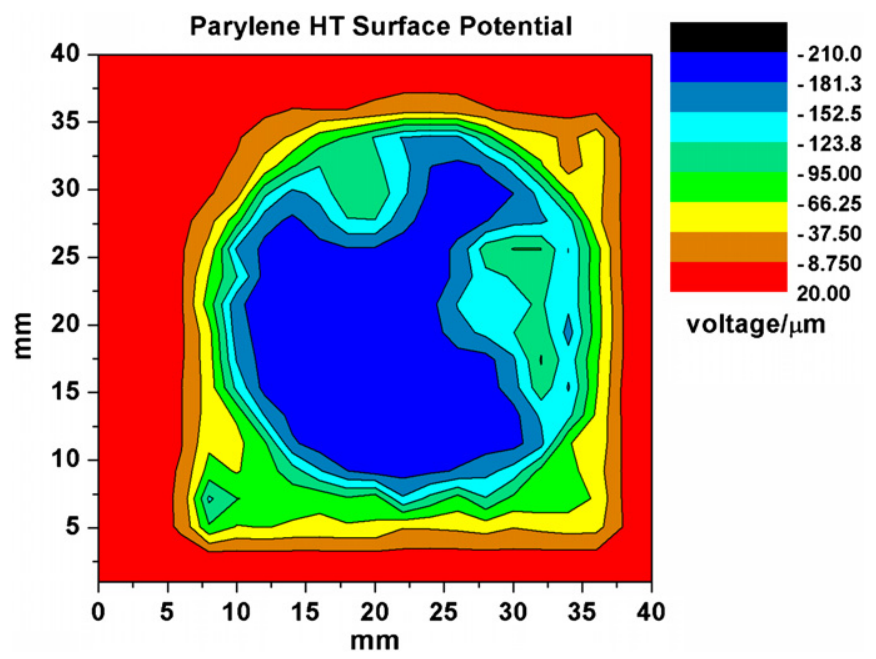

Figure 2. Distribution of the surface potential of a $7.32 \mu \mathrm{m}$ parylene $\mathrm{HT}^{\circledR}$ film.

Table 2. Corona charging conditions.

\begin{tabular}{ll}
\hline Base current & $0.02 \mu \mathrm{A}$ \\
Grid current & $0.2 \mu \mathrm{A}$ \\
Substrate temperature & $100{ }^{\circ} \mathrm{C}$ \\
Charging time & $60 \mathrm{~min}$ \\
\hline
\end{tabular}

and Nowlin from Union Carbide reported the first study on parylenes as electret materials [16], in which parylene $\mathrm{HT}^{\circledR}$ was referred to as 'polymer AF-4' but limited results were available. Unfortunately, after [16] no research was reported on parylene $\mathrm{HT}^{\circledR}$ as an electret material until this work, which is probably due to the unavailability of the material.

\subsection{Charging and charge density}

To study the charge retention property of parylene $\mathrm{HT}^{\circledR}$, parylene HT $^{\circledR}$ was first deposited on soda lime wafers. Next, samples coated with parylene $\mathrm{HT}^{\circledR}$ were implanted with electrons with the corona discharge method. The distribution of surface potential of charged parylene $\mathrm{HT}^{\circledR}{ }^{\circledR}$ was measured with an integrated system of Monroe Isoprobe ${ }^{\circledR}$ and a computer-controlled $x--y$ stage. Table 2 lists the conditions of corona charging. Different from other literatures, constant grid and base currents were employed, instead of constant needle and grid voltages. The corona charger is so controlled that the currents of the base and the grid were maintained at the values shown in table 2 by dynamically controlling the voltages of the needle and the grid with PID controlling algorithms. Figure 2 shows the space distribution of the charged sample. The highest surface potential observed was $204.58 \mathrm{~V} \mathrm{\mu m}^{-1}$, equivalent to a surface charge density of $3.69 \mathrm{mC} \mathrm{m}^{-2}$. The surface potential of the electret depends on the thickness of the electret. Under the same corona charging conditions, the thicker electret can achieve higher surface potential. Therefore, it is meaningful only when we compare the electric field, volt $\mu \mathrm{m}^{-1}$. The surface charge density can be calculated from this value. That is why we show the unit of volt $\mu \mathrm{m}^{-1}$ in figures 2 and 9 . 


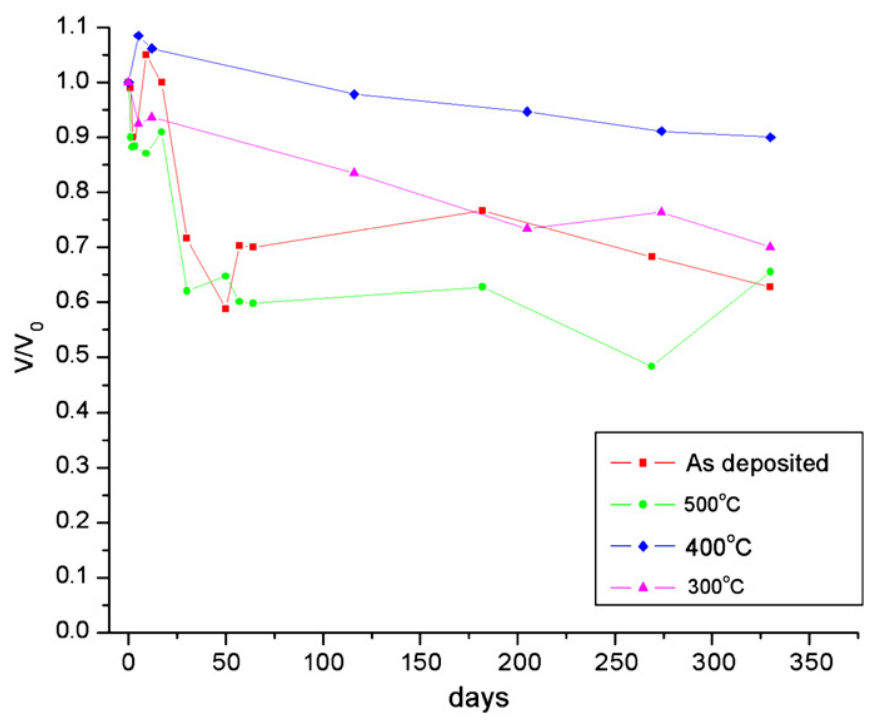

Figure 3. Temporal change of surface potentials of parylene $\mathrm{HT}^{\circledR}$ samples with different annealing treatments. Data shown here are normalized surface potential (against the initial values of each samples). As deposited, $500{ }^{\circ} \mathrm{C}, 400{ }^{\circ} \mathrm{C}$ and $300{ }^{\circ} \mathrm{C}$ refer to the samples that are as-deposited, annealed at $500{ }^{\circ} \mathrm{C}, 400^{\circ} \mathrm{C}$ and $300{ }^{\circ} \mathrm{C}$ for $1 \mathrm{~h}$ before charging, respectively.

\subsection{Long-term stability}

To study the stability and long-term reliability of charged parylene $\mathrm{HT}^{\circledR}$ films, parylene $\mathrm{HT}^{\circledR}$ samples were first annealed in a nitrogen ambient at $500{ }^{\circ} \mathrm{C}, 400{ }^{\circ} \mathrm{C}$ and $300{ }^{\circ} \mathrm{C}$ for $1 \mathrm{~h}$ before charging and the change of surface potential over time was monitored. Samples were stored at the room temperature and $60 \%$ RH. Figure 3 shows the decaying of the surface potential of parylene $\mathrm{HT}^{\circledR}$ annealed at different temperatures. The as-deposited parylene $\mathrm{HT}^{\circledR}$ sample and the sample annealed at $500{ }^{\circ} \mathrm{C}$ show a large initial drop of surface potential but maintain relatively stable values, around $65-70 \%$ of the initial value. Meanwhile, the surface charge density of the $400{ }^{\circ} \mathrm{C}$ annealed sample dropped to $91 \%$ of its initial value after 330 days. Since the measurement value scattered in a wide range, it is difficult to reach a solid conclusion of longterm reliability. However, this experiment still provides some information. To maintain as high power output as possible, $400{ }^{\circ} \mathrm{C}$ annealing may be a better choice since it could retain $91 \%$ of the initial surface potential, although it shows a continuous decreasing trend. In terms of stability and predictability, the as-deposited sample and $500{ }^{\circ} \mathrm{C}$ annealed sample provide an edge over the other two. Although they have initial drops of surface potential, the as-deposited sample and the $500^{\circ} \mathrm{C}$ annealed sample show fairly stable surface potential after 75 days. From the viewpoint of engineering, it would be preferable to have devices generating a lower power but more stable in time than the opposite. In short, it requires more data to arrive at a clear and firm conclusion. Further testing and more accurate measurement are currently underway.

\subsection{High-temperature reliability}

Thermally stimulated discharge (TSD) measurement was performed on charged parylene $\mathrm{HT}^{\circledR}$ samples in order to
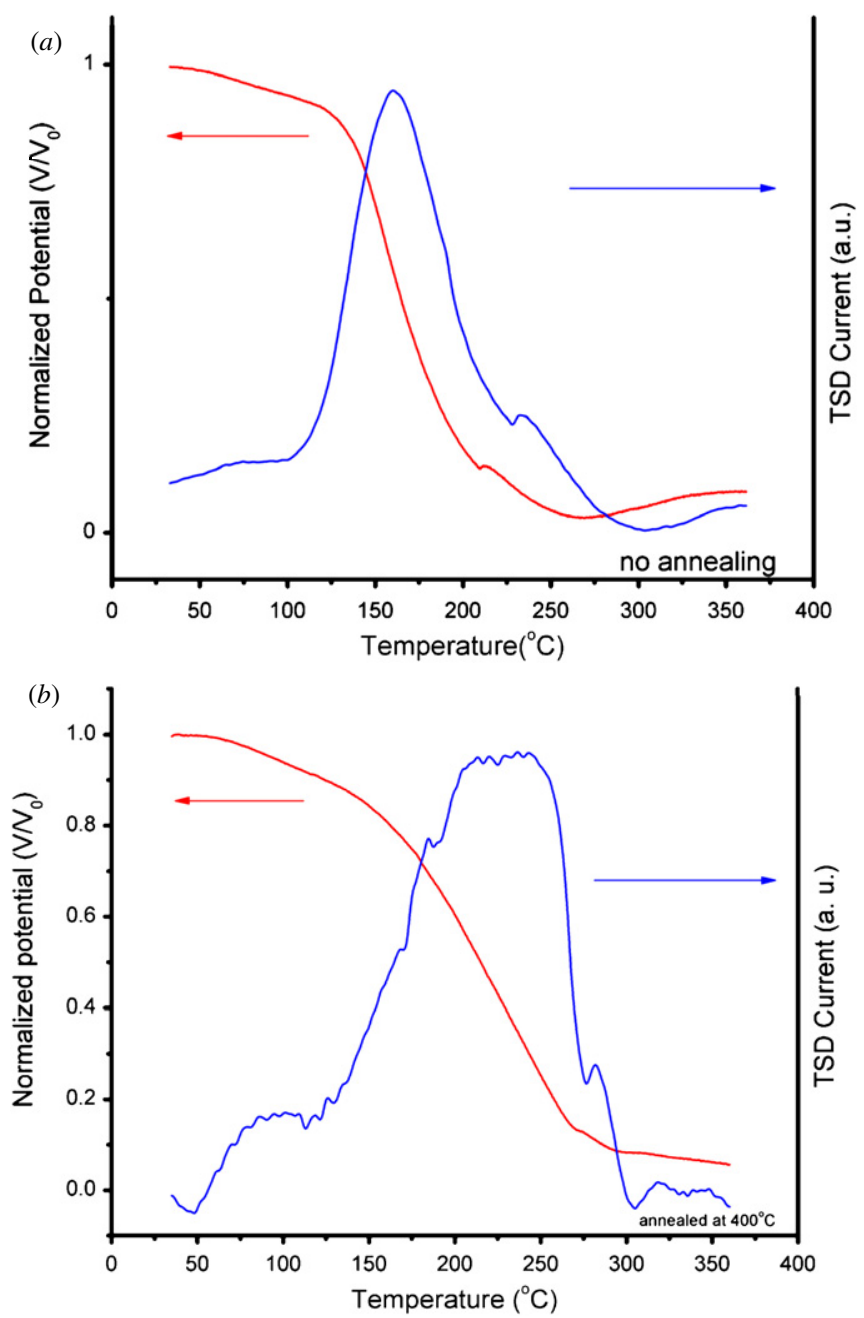

Figure 4. Thermally stimulated discharge (TSD) measurement of parylene $\mathrm{HT}^{\circledR}$ samples, $(a)$ without annealing and $(b)$ annealed at $400{ }^{\circ} \mathrm{C}$ for $1 \mathrm{~h}$ before charging. The surface potentials are normalized against initial values. The TSD current of parylene $\mathrm{HT}^{\circledR}$ samples is shown in an arbitrary unit.

understand their thermal stability and discharging mechanism. When an electret is heated, the dipoles and/or charges can be discharged at an accelerated rate depending on the temperature and the material. Therefore, during such a heat-stimulated discharge, an electret sandwiched between two electrodes can generate a discharging current that sometimes shows a number of peaks when recorded under a ramping temperature. The shape and peaks then reveal important information of the mechanisms by which the electret stores the charges [26]. In our case, we employed a modified TSD measurement. We measured both the discharging current and the surface potential as a function of the ramping temperature. The measuring electrode was therefore placed $1 \mathrm{~mm}$ above the sample and current was measured with a Keithley 485 autoranging picoammeter and surface potential was also monitored with Monroe Isoprobe. Samples were heated up at a rate of $1{ }^{\circ} \mathrm{C} \mathrm{min}-1$. Figure 4 shows the TSD current and surface potential of the non-annealed parylene $\mathrm{HT}^{\circledR}$ sample and the parylene $\mathrm{HT}^{\circledR}$ sample annealed at $400{ }^{\circ} \mathrm{C}$ for $1 \mathrm{~h}$ before charging. The peak TSD current occurred at around $160{ }^{\circ} \mathrm{C}$ 


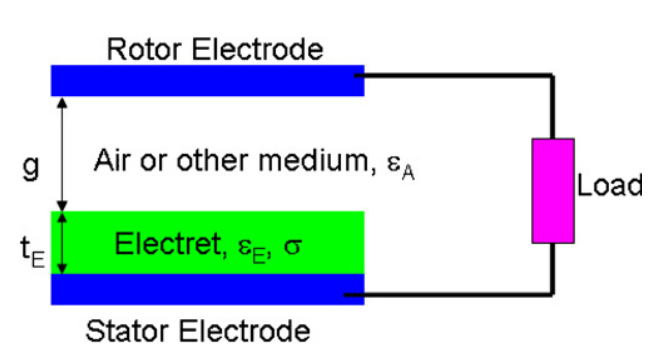

Figure 5. Common design of micro electret power generators.

for the parylene $\mathrm{HT}^{\circledR}$ samples without annealing and $230{ }^{\circ} \mathrm{C}$ for the samples annealed at $400{ }^{\circ} \mathrm{C}$ for $1 \mathrm{~h}$ before charging. A higher TSD peak temperature means a better capability to withstand high temperature [26]. It is found that precharging annealing improves the high-temperature reliability of parylene $\mathrm{HT}^{\circledR}$.

\section{Design of micro electret power generators}

Generally, electrostatic power generators can be classified into three categories: variable in-plane overlap, variable inplane gap and variable out-of-plane gap [2]. For micro electret power generators, a variable in-plane gap configuration (figure 5) has been widely used since the first micro electret power generator [3]. The power output from such micro electret power generators is given as

$$
P_{\mathrm{MAX}}=\frac{\sigma^{2}}{\frac{4 \varepsilon_{0} \varepsilon_{\mathrm{E}}}{t_{\mathrm{E}}}\left(\frac{\varepsilon_{\mathrm{E}} g}{\varepsilon_{\mathrm{A}} t_{\mathrm{E}}}+1\right)} \cdot \frac{\mathrm{d} A(t)}{\mathrm{d} t},
$$

where $\sigma$ is the surface charge density, $\varepsilon_{0}$ is the vacuum permittivity, $\varepsilon_{\mathrm{E}}$ is the dielectric constant of the electret, $\varepsilon_{\mathrm{A}}$ is the dielectric constant of air (i.e. $\sim 1$ ), $g$ is the gap distance from the top electrode to the electret surface, $t_{\mathrm{E}}$ is the electret thickness and $A(t)$ is the variable overlap area between the top and bottom electrodes.

From equation (1), the power output of micro electret power generators depends on several factors, such as the gap distance, $g$, the thickness of the electret material, $t_{\mathrm{E}}$, etc. Typical values of $\varepsilon_{\mathrm{E}}$, the dielectric constant of polymer electrets, are around 2 (2.2 for parylene $\mathrm{HT}^{\circledR}, 2.1$ for CYTOP, 1.9 for Teflon AF and 2.1 for PTFE). Therefore, when the gap distance is larger than two times the electret thickness, the gap distance plays a dominant role for the output power. To maximize the output power, it is desirable to have as small a gap distance relative to the thickness of the electret as possible. The largest state-of-the-art thickness of electrets is $20 \mu \mathrm{m}$ of CYTOP, achieved by several consecutive spin coatings [25]. With this constraint, the gap distance has to be controlled within around $50 \mu \mathrm{m}$. In [25], the gap distance is controlled to be $100 \mu \mathrm{m}$ with precise $x-y-z$ stages, while it is $500 \mathrm{~nm}$ in [20] with a spin-coated polymer gasket and $1000 \mu \mathrm{m}$ in [4] with PDMS-formed chambers. The need for gap-controlling structures often complicates the generator design and fabrication.

To eliminate the gap-controlling problem, a new design is used here. Different from the conventional variable in-plane gap design, this new design has both electrodes on the stator, as shown in figure 6 . Image charges on the electrodes are induced by the surface charges on the electret material. When the rotor moves relative to the stator, induced charges on the electrodes vary with the position of the rotor. Current flow is thus created (figure 7). Based on this, two configurations are possible. One consists of a metal rotor and a stator covered with an electret, while the other is composed of an electretcoated rotor and a bare stator with output electrodes. When the electret-coated rotor is made out of insulators, the second configuration is expected to have larger power output since the induced charge density on the output electrodes is higher than that in the first configuration.

In these two designs, power is transduced into the load via charge induction and no gap control is required. Since no electrode is needed on the rotor, the rotor can be simply a moving object, made of metal or dielectric. One major advantage of this design is that there is no tethering spring attached to the rotor, so there is no mechanical resonance (i.e. resonant frequency near zero). This means that the generator can work at very low frequency as long as the relative motional force can break the frictional force induced by the attractive electrostatic force between the electret charges and their image charges on the electrodes.

\section{Prototype device fabrication and characterization}

To demonstrate the novel concept of electret power generation, we fabricated the prototypes with conventional machining
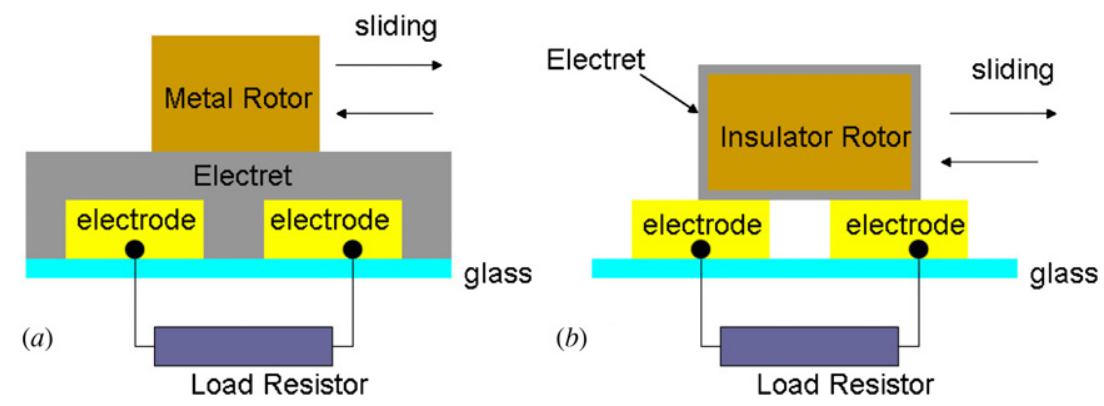

Figure 6. Schematics of two new designs of micro electret power generators. The two output electrodes of both designs are placed on the stator. (a) This device uses a metal rotor and an electret-coated stator. (b) This device uses an electret-coated insulating rotor and a bare stator. 

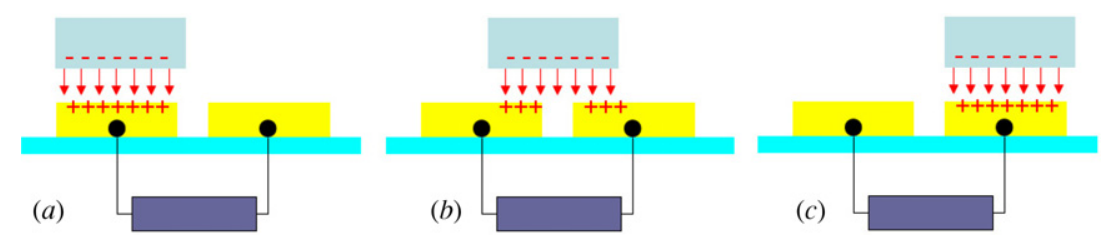

Figure 7. Illustration of power generation from the generator with an electret-coated insulating rotor. When the rotor moves from $(a),(b)$ to $(c)$, the final equilibrium image charges on the left electrode decrease, those on the right electrode increase and a net current flows from the left electrode through the load to the right electrodes. Next, when the rotor moves from $(c),(b)$ to $(a)$, the current reverses and thus completes a power generation cycle.

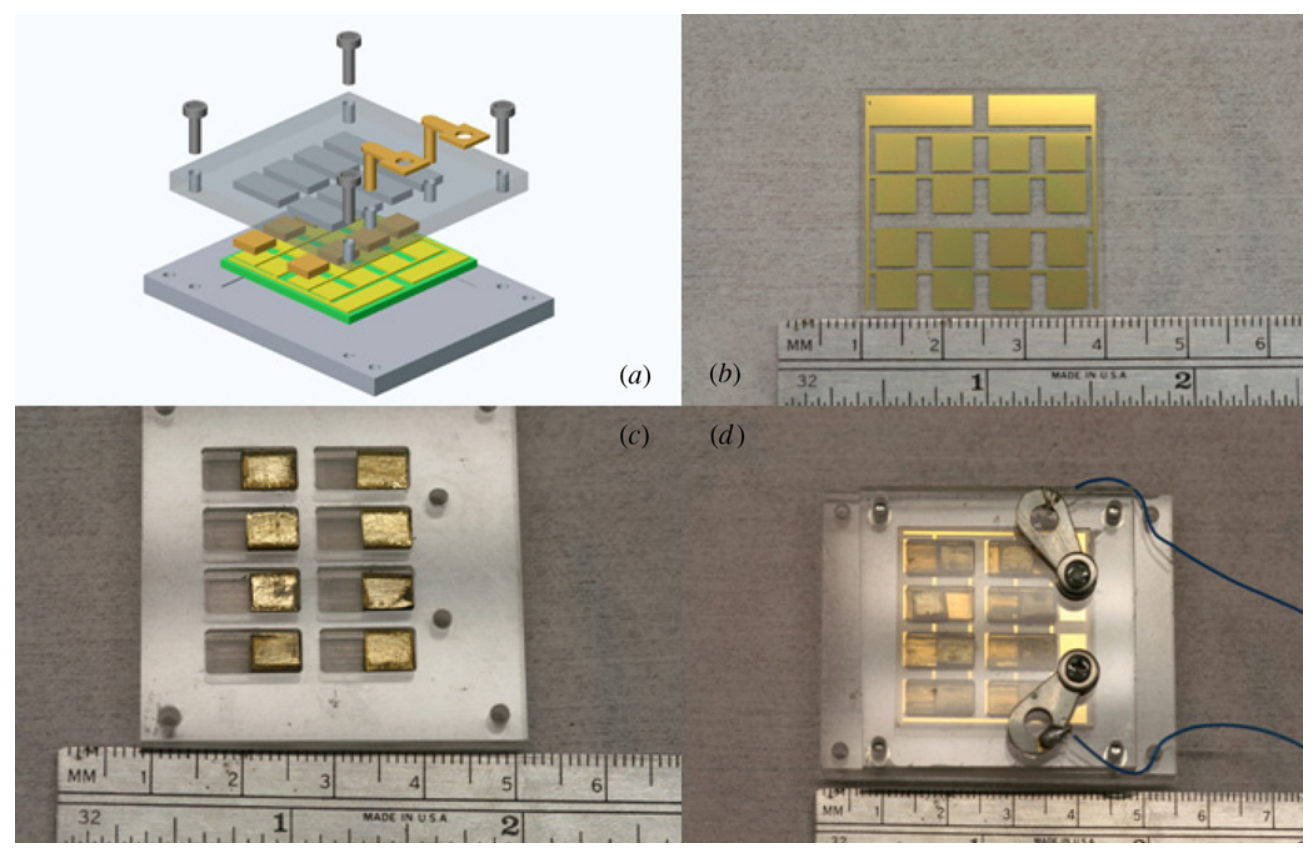

Figure 8. An electret generator with metal rotors. (a) Schematic of the generator assembly, $(b)$ a parylene $\mathrm{HT}^{\circledR}{ }^{\circledR}$-coated stator, $(c)$ the metal rotors and $(d)$ the final assembly.

processes, rather than the microfabricating process. This facilitates us to conveniently and readily characterize the prototype devices and verify our theory of power generation. It is worth mentioning that future devices can be easily fabricated with microfabrication with little modification of the demonstrated prototype devices, although the prototype devices have large dimensions.

\subsection{Device with metal rotors}

Fabrication of generators started with soda lime glass wafers. $200 \mathrm{~nm} \mathrm{Au}$ and $10 \mathrm{~nm} \mathrm{Cr}$ were thermally evaporated and patterned as the power output electrodes via conventional photolithographic processes. The electrodes are $5 \mathrm{~mm} \times 5 \mathrm{~mm}$ with $2 \mathrm{~mm}$ spacing for each cell. Next, the glass wafer was diced into $30 \mathrm{~mm} \times 30 \mathrm{~mm}$ stators. After dicing, $7.32 \mu \mathrm{m}$ parylene $\mathrm{HT}^{\circledR}$ is deposited on the stator. Similar to parylene $\mathrm{C}$ and other parylene variants, parylene $\mathrm{HT}^{\circledR}$ is deposited via the room temperature CVD process. After deposition, corona charging is done to implant electrons on parylene $\mathrm{HT}^{\circledR}$. Charging conditions are listed in table 2 . The rotors are machined to be $4.5 \mathrm{~mm} \times 4.5 \mathrm{~mm} \times 2 \mathrm{~mm}(L \times W \times H)$ brass blocks. The container is also machined out of acrylic material. The final assembled device is shown in figure 8 .

\subsection{Device with parylene $H T^{\circledR}$-coated insulator rotors}

The fabrication of this device began with machining the polyetheretherketone (PEEK) rotor blocks. The dimensions of the rotor blocks are $5 \mathrm{~mm} \times 6 \mathrm{~mm} \times 9 \mathrm{~mm}(L \times W \times \mathrm{H})$. Similar to the devices aforementioned, the stator is simply a piece of glass with patterned electrodes. $150 \mathrm{~nm}$ gold and $10 \mathrm{~nm}$ chromium are deposited on soda lime wafers. The metal film is then patterned to be $5 \mathrm{~mm} \times 5 \mathrm{~mm}$ square pads with conventional photolithography. $7.32 \mu \mathrm{m}$ of parylene $\mathrm{HT}^{\circledR}$ is deposited onto the PEEK rotor and then charged via corona charging. Charging conditions are also the same as in table 2. Figure 9 shows the surface potential distribution of eight pieces of PEEK rotor blocks after charging. An external acrylic packaging container was made to confine the movement of rotors. Figure 10 shows the PEEK rotor block, the electrode stator and the device assembly.

\subsection{Power output}

The assembled generators were mounted onto a machined acrylic stage fixed to an electrodynamic shaker, as shown in figure $10(d)$. All necessary wires were soldered. Power generation experiments were performed using a Labworks 

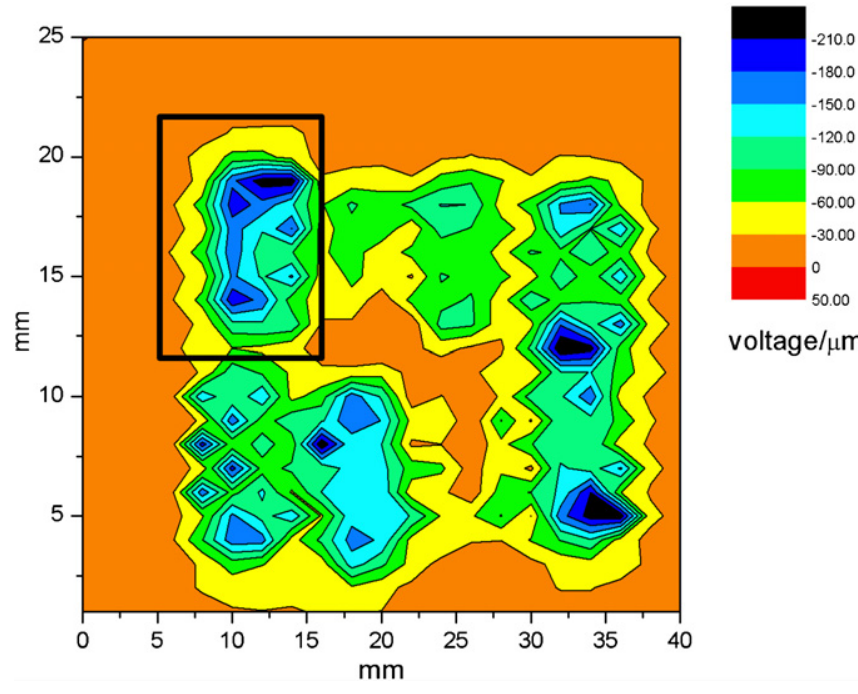

voltage $/ \mu \mathrm{m}$

Figure 9. The surface potential of parylene $\mathrm{HT}^{\circledR}$ coated on PEEK rotor blocks. There are eight PEEK blocks in the figure and one block is identified with a black rectangle frame.

Inc. ET-132-2 electrodynamic shaker, which was driven sinusoidally by an HP33120A function generator through a power amplifier. The acceleration of the power generator was measured with an Endevco256HX-10 accelerometer. The micro electret power generators were connected to resistive loads. In order to measure large output voltages, a simple two-resistor voltage divider was used as the load. The output voltage was measured through a National Semiconductor LF356N op-amp, a $10^{12} \Omega$ input impedance voltage buffer. The maximal shaking amplitude, $5 \mathrm{~mm}$, was defined by the external packaging container. The frequency varied from $10 \mathrm{~Hz}$ to $70 \mathrm{~Hz}$ and the load resistance from 50 to $2000 \mathrm{M} \Omega$.

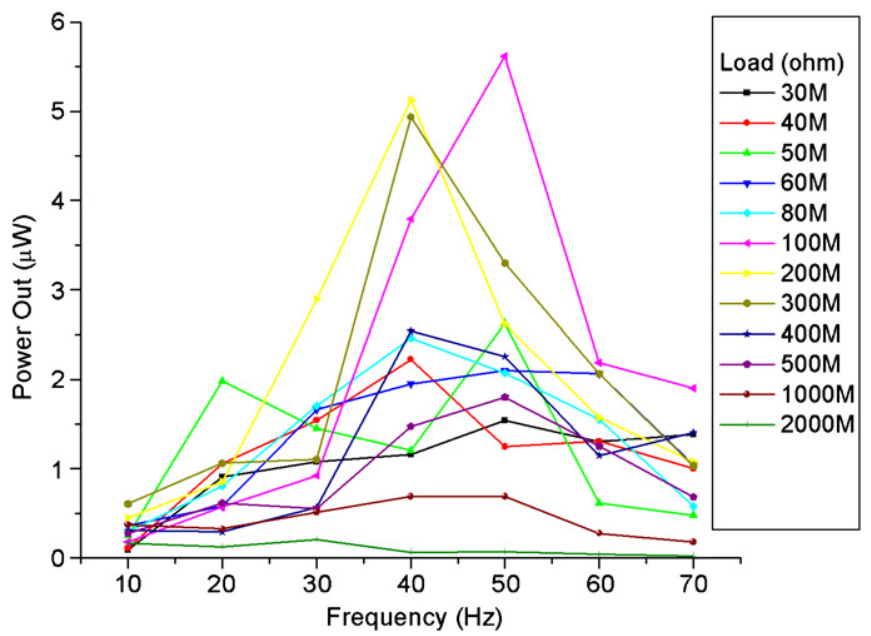

Figure 11. Power versus frequency for the generator with metal rotors.

Figures 11 and 12 show power outputs of both devices as a function of frequency. The maximum power output, $17.98 \mu \mathrm{W}$, was obtained at $50 \mathrm{~Hz}$ with an external load of $80 \mathrm{M} \Omega$ for the generator with parylene $\mathrm{HT}^{\circledR}{ }^{\circledR}$-coated PEEK rotors. As the devices are aimed to harvest power from natural vibrations, the low-frequency performance is of special interest. The generator with parylene $\mathrm{HT}^{\circledR}$-coated PEEK rotors can harvest $7.7 \mu \mathrm{W}$ at $10 \mathrm{~Hz}$ and $8.23 \mu \mathrm{W}$ at $20 \mathrm{~Hz}$.

As expected, the generator with PEEK rotors produces larger power than that with metal rotors. The ratio is close to 4 . This can be explained by the fact that the induced charge density on the electrodes of the generator with PEEK rotors is twice that of the generator with metal rotors. According

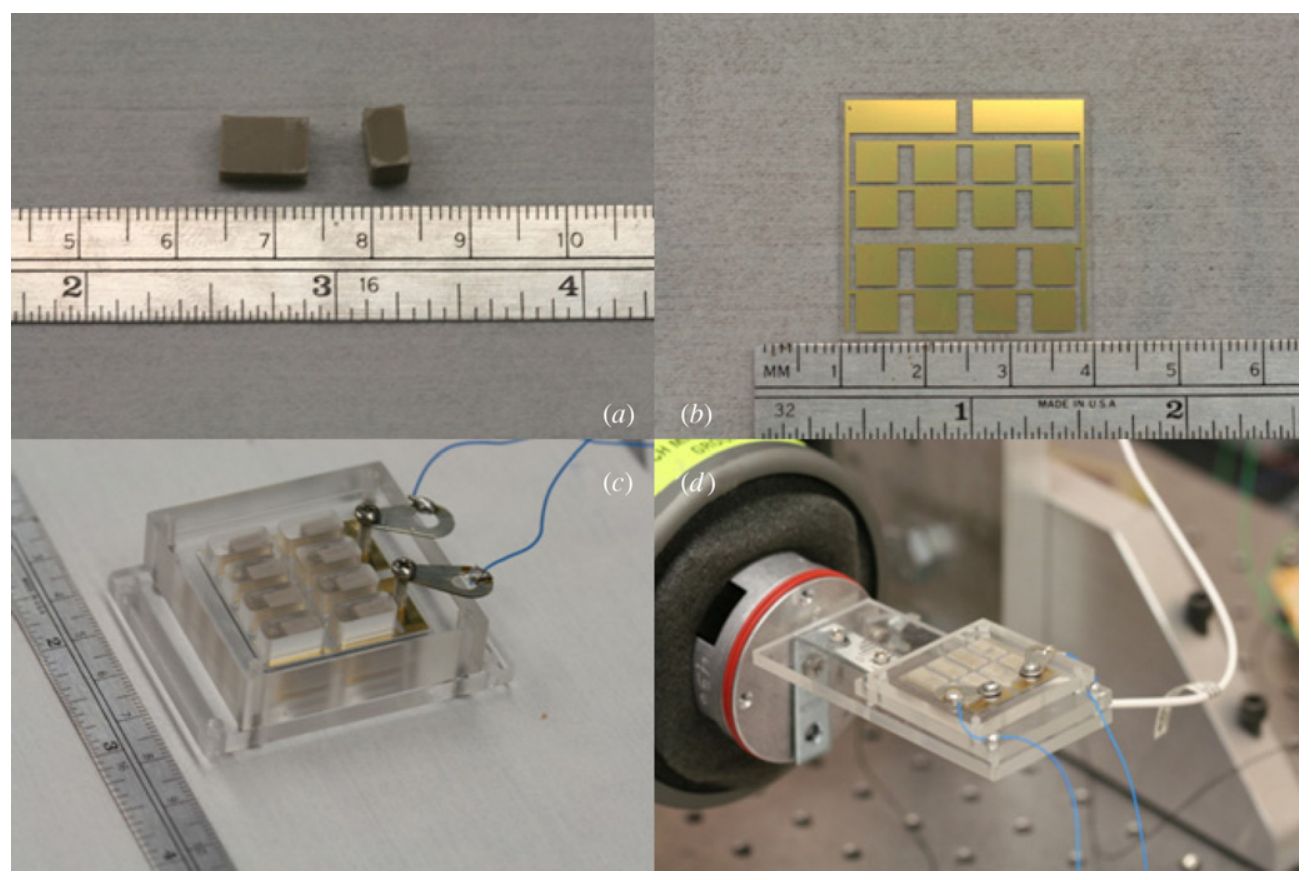

Figure 10. An electret generator with parylene $\mathrm{HT}^{\circledR}{ }^{\circledR}$-coated PEEK rotors: $(a)$ parylene $\mathrm{HT}^{\circledR}{ }^{\circledR}$-coated PEEK rotors, $(b)$ a bare stator, $(c)$ the assembled generator and $(d)$ the generator assembly mounted on a shaker. 


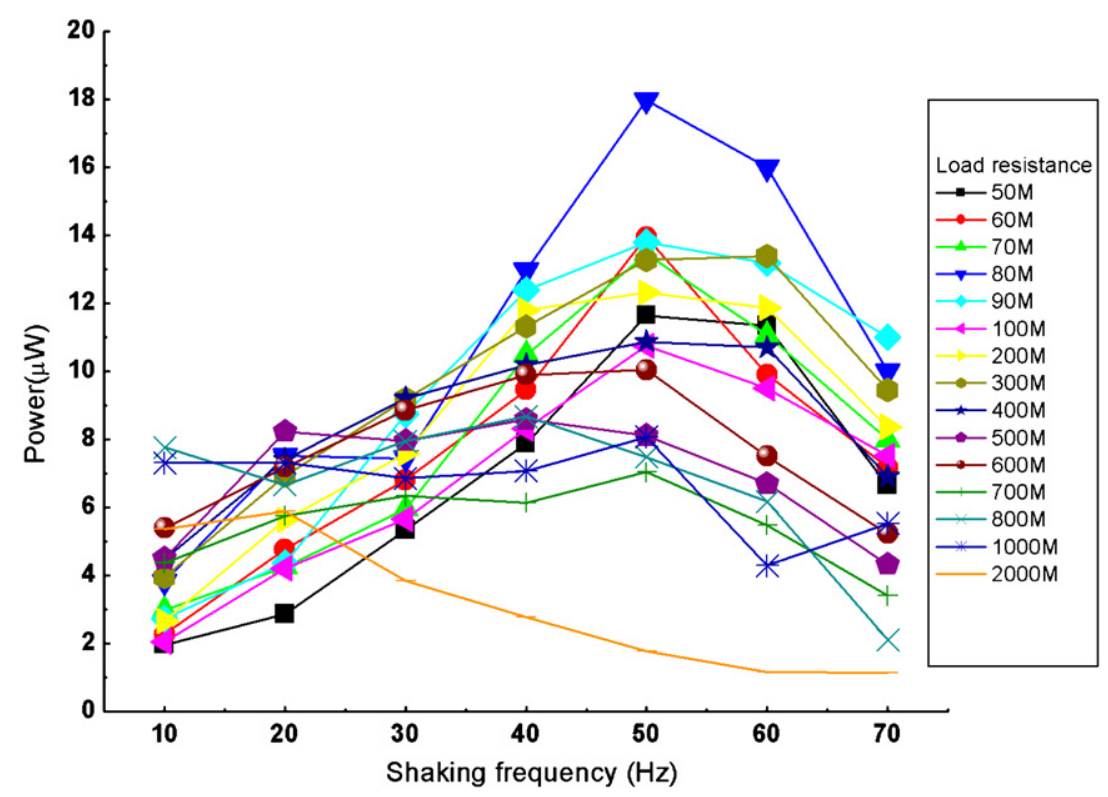

Figure 12. Power versus frequency for the generator with parylene $\mathrm{HT}^{\circledR}{ }^{\circledR}$-coated PEEK rotors.

to equation (1), power output is proportional to the square of charge density.

The device can fully deliver its power as designed only when the rotor moves completely from one electrode to the other, which is equivalent to the shaking amplitude of $5 \mathrm{~mm}$. However, due to the limitation of the shaker, it was impossible to produce enough energy for the rotor to have $5 \mathrm{~mm}$ amplitudes at frequencies higher than $50 \mathrm{~Hz}$. According to the specifications of the ET-132-2 electrodynamic shaker, the maximum peak sine output force is 7 pounds, equivalent to 31.136 Newton. The maximum acceleration the shaker could exert on the power generator assembly is around $576.6 \mathrm{~m} \mathrm{~s}^{-2}$, since the power generator assembly has $54 \mathrm{~g}$ mass. The maximum displacement of the shaker is $5.84 \mathrm{~mm}$ at $50 \mathrm{~Hz}$, $4.05 \mathrm{~mm}$ at $60 \mathrm{~Hz}$ and $2.98 \mathrm{~mm}$ at $70 \mathrm{~Hz}$ (displacement is calculated by assuming that the shaking motion is ideal simple harmonic.) At higher frequencies, the rotor only partially moves in its supposed amplitude and hence the generator produces less power. Based on the information, we can say that the shaker's failure to provide enough shaking amplitude at frequencies higher than $50 \mathrm{~Hz}$ is at least a factor that the overall output power decreases in the frequency range higher than $50 \mathrm{~Hz}$. This phenomenon results from the large dimensions of the rotors. It can be improved with smaller rotors, smaller confining chambers and thus smaller shaking amplitudes.

To correctly assess the capability of a micro power generator, power density should be used. For our devices, the total volume including the external container is $50 \mathrm{~cm}^{3}$. Taking this into consideration, the power density of these devices is around $0.36 \mu \mathrm{W}$ per $\mathrm{cm}^{3}$ at $50 \mathrm{~Hz}$. It seemed very low. However, the first generation of these devices has a lot of unnecessary volume. Most of the unused volume comes from external package and the rotor blocks. To improve the power densities, one can carefully design an external packaging container that requires the least amount of volume. Besides, the PEEK rotors of the second device have a dimension of $5 \mathrm{~mm} \times 6 \mathrm{~mm} \times 9 \mathrm{~mm}$ so that it has enough mass to overcome the electrostatic attraction forces between the rotor and stator electrodes during vibration. Choosing other insulating materials that have higher densities may further reduce the volume of the electret rotors and thus the total volume of the fabricated generator. Power density may further be improved. Large-area and stackable designs can also increase the total power output.

Large optimal load resistance has always plagued electretbased power generators, preventing wide applications of such devices. Boland et al produced $25 \mu \mathrm{W}$ with $7.6 \mathrm{M} \Omega$ [3], Tsutsumino et al produced $38 \mu \mathrm{W}$ with $60 \mathrm{M} \Omega$ [25] and Sterken et al produced $5 \mu \mathrm{W}$ with $40 \mathrm{M} \Omega$ [20]. It is the nature of electret power generators to produce outputs with large voltage but small current. We are currently actively looking for effective methods of power management that fit the special requirement of electret power generators. One possible and easy method would be connecting in parallel as many generator cells as possible to provide large enough current. There are only eight cells in the prototype device. The more the cells are, the higher the power output is. Thus we can lower the load resistance while maintaining large enough power, although it is not optimal. Besides, shrinking the dimension of cells with microfabrication processes can increase the number of cells per device and reduce the shaking amplitude, generate higher current under the same condition and thus lower the required load resistance while producing large enough power.

\section{Conclusion}

We developed a new electret based on the CVD parylene $\mathrm{HT}^{\circledR}$ thin-film material. The new parylene $\mathrm{HT}^{\circledR}$ electret is studied in terms of process, stability, temperature reliability and optimization. The highest charge density observed of parylene $\mathrm{HT}^{\circledR}$ was $3.69 \mathrm{mC} \mathrm{m}^{-2}$, which is significantly higher than other polymer electrets. Annealing at $400{ }^{\circ} \mathrm{C}$ for $1 \mathrm{~h}$ 
before charging greatly improved the long-term stability and high-temperature reliability of parylene $\mathrm{HT}^{\circledR}$. Two designs of electret generators were then fabricated and characterized. The maximum power output was $17.98 \mu \mathrm{W}$ at $50 \mathrm{~Hz}$ with an external load of $80 \mathrm{M} \Omega$. At low frequencies, this generator also produced decent power outputs such as $7.7 \mu \mathrm{W}$ at $10 \mathrm{~Hz}$ and $8.23 \mu \mathrm{W}$ at $20 \mathrm{~Hz}$.

\section{Acknowledgments}

The authors would like to thank all members from the Caltech Micromachining Laboratory for their assistance on design, fabrication and testing of this device, especially Mr Trevor Ropers for his assistance with equipment and fabrication processes.

\section{References}

[1] Amjadi H 1999 Charge storage in double layers of thermally grown silicon dioxide and APCVD silicon nitride IEEE Trans. Dielectr. Electr. Insul. 6 852-7 (also see IEEE Trans. Electr. Insul.)

[2] Beeby S P 2006 Energy harvesting vibration sources for microsystems applications Meas. Sci. Technol. 17 R175

[3] Boland J, Chao Y H, Suzuki Y and Tai Y C 2003 Micro electret power generator IEEE 16th Ann. Int. Conf. Micro Electro Mechanical Systems, 2003 (MEMS-03) (Kyoto) pp 538-41

[4] Boland J S, Messenger J D M, Lo H W and Tai Y C 2005 Arrayed liquid rotor electret power generator systems $18 \mathrm{th}$ IEEE Int. Conf. Micro Electro Mechanical Systems, 2005 (MEMS 2005) pp 618-21

[5] Boland J S and Tai Y C 2004 Liquid-rotor electret micropower generator Solid-State Sensor, Actuator, and Microsystems Workshop

[6] Challa V R 2008 A vibration energy harvesting device with bidirectional resonance frequency tunability Smart Mater. Struct. 17015035

[7] Elvin N, Elvin A and Choi D 2003 A self-powered damage detection sensor J. Strain Anal. Eng. Des. 38 115-24

[8] Hsieh W, Hsu T and Tai Y 1997 A micromachined thin-film Teflon electret microphone Transducers '97, Solid-State Sensors and Actuators (Chicago, IL: IEEE) p 2B.02

[9] Hsieh W H, Yao T-J and Tai Y-C 1999 A high performance MEMS thin-film Teflon electret microphone Transducers '99 10th Int. Conf. Solid-State Sensors and Actuators (Sendai: Institute of Electrical Engineers of Japan) pp 1064-7

[10] Kulah H and Najafi K 2004 An electromagnetic micro power generator for low-frequency environmental vibrations 17 th IEEE Int. Conf. Micro Electro Mechanical Systems, 2004 (MEMS '04) ed K Najafi pp 237-40

[11] Kymissis J, Kendall C, Paradiso J A and Gershenfeld N 1998 Parasitic power harvesting in shoes 2 nd Int. Symp. Wearable Computers (ISWC'98) p 132
[12] Lo H W and Tai Y C 2008 Parylene-HT-based electret rotor generator IEEE 21 st Int. Conf. Micro Electro Mechanical Systems, 2008 (MEMS 2008) pp 984-7

[13] Mateu L and Moll F 2005 Optimum piezoelectric bending beam structures for energy harvesting using shoe inserts J. Intell. Mater. Syst. Struct. 16 835-45

[14] Mitcheson P D, Miao P, Stark B H, Yeatman E M, Holmes A S and Green T C 2004 MEMS electrostatic micropower generator for low frequency operation Sensors Actuators A 115 523-9

[15] Ottman G K, Hofmann H F and Lesieutre G A 2003 Optimized piezoelectric energy harvesting circuit using step-down converter in discontinuous conduction mode IEEE Trans. Power Electron. 18 696-703

[16] Raschke C R and Nowlin T E 1980 Polyparaxylylene electrets usable at high temperatures J. Appl. Polym. Sci. $251639-44$

[17] Roundy S 2004 A piezoelectric vibration based generator for wireless electronics Smart Mater. Struct. 131131

[18] Shearwood C and Yates R B 1997 Development of an electromagnetic microgenerator Electron. Lett. 33 1883-4

[19] Shenck N S and Paradiso J A 2001 Energy scavenging with shoe-mounted piezoelectrics IEEE Micro 21 30-42

[20] Sterken T, Fiorini P, Altena G, Van Hoof C A V H C and Puers R A P R 2007 Harvesting energy from vibrations by a micromachined electret generator Int. Conf. Solid-State Sensors, Actuators and Microsystems Conf., 2007 ed P Fiorini pp 129-32

[21] Sterken T, Fiorini P, Baert K, Puers R A P R and Borghs G A B G 2003 An electret-based electrostatic micro-generator Transducers 12th Int. Conf. Solid-State Sensors, Actuators and Microsystems, 2003 ed P Fiorini pp 1291-4

[22] Tashiro R 2000 Development of an electrostatic generator that harnesses the motion of a living body:(use of a resonant phenomenon) JSME Int. J. A 43916

[23] Torfs T, Leonov V, Van Hoof C and Gyselinckx B 2006 Body-heat powered autonomous pulse oximeter 5th IEEE Conf. Sensors, 2006 pp 427-30

[24] Tsutsumino T, Suzuki Y and Kasagi N 2007 Electromechanical modeling of micro electret generator for energy harvesting Transducers 2007, Int. Conf. Solid-State Sensors, Actuators and Microsystems, 2007 ed Y Suzuki pp 863-6

[25] Tsutsumino T, Suzuki Y, Kasagi N and Sakane Y S A-Y 2006 Seismic power generator using high-performance polymer electret 19th IEEE Int. Conf. Micro Electro Mechanical Systems, 2006 (MEMS 2006) (Istanbul) ed Y Suzuki pp 98-101

[26] van Turnhout J 1998 Electrets ed G M Sessler (Morgan Hill, CA: Laplacian) pp 84-98

[27] von Buren T and Troster G 2007 Design and optimization of a linear vibration-driven electromagnetic micro-power generator Sensors Actuators A 135 765-75

[28] Williams C B, Shearwood C, Harradine M A, Mellor P H A M P H, Birch T S A B T S and Yates R B A Y R B 2001 Development of an electromagnetic micro-generator IEE Proc. G 148 337-42

[29] Wu J, Zhang R R, Wu Q and Stevens K K 2003 Environmental vibration assessment and its applications in accelerated tests for medical devices J. Sound Vib. 267 371-83 